\title{
Enhancing DNA Vaccine Potency by Combining a Strategy to Prolong Dendritic Cell Life and Intracellular Targeting Strategies with a Strategy to Boost CD4+ T Cells
}

\author{
DAEJIN KIM ${ }^{1}$, TALIA HOORY ${ }^{1}$, T.-C. WU $1,2,3,4$, and CHIEN-FU HUNG ${ }^{1,4}$ \\ 1Department of Pathology, Johns Hopkins Medical Institutions, Baltimore, MD 21231 \\ ${ }^{2}$ Department of Obstetrics and Gynecology, Johns Hopkins Medical Institutions, Baltimore, MD \\ 21231 \\ ${ }^{3}$ Department of Molecular Microbiology and Immunology, Johns Hopkins Medical Institutions, \\ Baltimore, MD 21231 \\ ${ }^{4}$ Department of Oncology, Johns Hopkins Medical Institutions, Baltimore, MD 21231
}

\begin{abstract}
Intradermal administration of DNA vaccines, using a gene gun, represents an effective means of delivering DNA directly into professional antigen-presenting cells (APCs) in the skin and thus allows the application of strategies to modify the properties of APCs to enhance DNA vaccine potency. In the current study, we hypothesized that the potency of human papillomavirus (HPV) type 16 E7 DNA vaccines employing intracellular targeting strategies combined with a strategy to prolong the life of dendritic cells (DCs) could be further enhanced by the addition of a DNA vaccine capable of generating high numbers of pan-HLA-DR reactive epitope (PADRE)-specific $\mathrm{CD} 4^{+} \mathrm{T}$ cells. We observed that the addition of PADRE DNA to E7 DNA vaccines employing intracellular targeting strategies with a strategy to prolong the life of DCs led to significant enhancement of E7-specific $\mathrm{CD} 8^{+}$effector and memory $\mathrm{T}$ cells as well as significantly improved therapeutic effects against established E7-expressing tumors in tumor-challenged mice. Our data suggest that the potency of a DNA vaccine combining an intracellular targeting strategy as well as a strategy to prolong the life of DCs can be further enhanced by addition of DNA that is capable of generating high numbers of PADRE-specific $\mathrm{CD} 4^{+} \mathrm{T}$ cells.
\end{abstract}

\section{INTRODUCTION}

DNA vaccines have emerged as a favorable approach for antigen-specific immunotherapy because of their safety, stability, and ease of production. Administration of DNA vaccines intradermally, using a gene gun, represents an effective means of delivering DNA directly into the professional antigen-presenting cells in the skin, the Langerhans cells, which are a form of immature dendritic cell (DC). The DNA-expressing DCs mature and migrate to the draining lymph nodes, where they activate naive T lymphocytes in vivo to differentiate into activated helper or killer T cells (Condon et al., 1996; Porgador et al., 1998). With the gene gun administration system, we have been able to modify the properties of dendritic cells,

\footnotetext{
(C) Mary Ann Liebert, Inc.

Address reprint requests to: Dr. Chien-Fu Hung, Departments of Pathology and Oncology, School of Medicine, Johns Hopkins University, CRBII Room 307, 1550 Orleans Street, Baltimore, MD 21231, chung2@jhmi.edu.

AUTHOR DISCLOSURE STATEMENT

For all authors, no competing financial interests exist.
} 
using a number of strategies to enhance DNA vaccine potency (for review, see Hung et al., 2006; Tsen et al., 2007).

One strategy to enhance DNA vaccine potency is to improve the MHC class I and class II presentation of model antigens, using an intracellular targeting strategy (for review, see Moniz et al., 2003; Hung et al., 2006; Tsen et al., 2007). For example, we have previously shown that DNA vaccines encoding human papillomavirus type 16 (HPV-16) E7 antigen linked to calreticulin (CRT) (Cheng et al., 2001a) or the targeting signal of lysosomeassociated membrane protein 1 (LAMP-1) (Ji et al., 1999) were capable of generating potent E7-specific $\mathrm{CD}^{+} \mathrm{T}$ cell immune responses in vaccinated mice compared with DNA encoding unmodified E7 antigen. Furthermore, mice vaccinated with the DNA vaccines encoding Sig/E7/LAMP-1 or CRT/E7 have been shown to generate stronger antitumor effects against E7-expressing tumors when compared with mice vaccinated with wild-type E7 DNA.

Another strategy to enhance DNA vaccine potency is to prolong the life of the antigenexpressing DCs. We have previously employed DNA vaccines coadministered with DNA encoding antiapoptotic proteins to enhance DNA vaccine potency (for review, see Hung et al., 2006; Tsen et al., 2007). For example, Kim and coworkers have tested the intradermal administration of E7 DNA vaccines in conjunction with DNA encoding antiapoptotic proteins such as Bcl- $\mathrm{x}_{\mathrm{L}}$ (B cell leukemia/lymphoma extra long), Bcl-2, XIAP (X-linked inhibitor of apoptosis protein), dominant-negative caspase-8, or dominant-negative caspase-9 vaccines for their ability to enhance DNA vaccine potency in vaccinated mice (Kim et al., 2003a). They showed that coadministration of E7 DNA vaccines with DNA encoding any of these antiapoptotic proteins was capable of enhancing E7-specific CD8 ${ }^{+} \mathrm{T}$ cell-mediated immune responses and of generating potent antigen-specific antitumor effects in vaccinated mice. Among the antiapoptotic proteins examined, Kim and coworkers found DNA encoding Bcl- $\mathrm{x}_{\mathrm{L}}$ to be the most effective in enhancing DNA vaccines when the DNAs were administered together (Kim et al., 2003a). Because the intracellular targeting strategies and the strategies to prolong the life of DCs represented different mechanisms to modify the properties of DCs, Kim and coworkers combined these two strategies by coadministration of Bcl- $x_{L}$ DNA and Sig/E7/LAMP-1 DNA, which employed intracellular targeting strategies, to determine the effect of the DNA vaccines in generating antigen-specific immune responses and antitumor effects in vaccinated mice. They found that DNA vaccines employing these two strategies are capable of further enhancing the E7-specific CD8 ${ }^{+} \mathrm{T}$ cell immune responses in vaccinated mice compared with DNA vaccines employing each of these strategies alone (Kim et al., 2003a).

More recently, we have developed an innovative strategy to enhance DNA vaccine potency by coadministration of DNA vaccines with another DNA vaccine construct that is capable of generating high numbers of antigen-specific $\mathrm{CD} 4^{+} \mathrm{T}$ cells in vaccinated mice. It is now clear that $\mathrm{CD} 4^{+} \mathrm{T}$ cells play a critical role in the production of cytotoxic and memory $\mathrm{T}$ cell populations (for review, see Castellino and Germain, 2006). We previously enhanced the $\mathrm{CD}^{+} \mathrm{T}$ cell immune responses in mice by constructing a DNA vaccine encoding an invariant (Ii) chain in which the class II-associated Ii peptide (CLIP) region is replaced with a CD4 ${ }^{+}$helper T epitope, PADRE (invariant pan-HLA-DR reactive epitope) to form IiPADRE. C57BL/6 mice vaccinated with DNA encoding Ii-PADRE showed significantly greater PADRE-specific $\mathrm{CD} 4^{+} \mathrm{T}$ cell immune responses than did mice vaccinated with DNA encoding the Ii chain alone (Ii DNA). More important, administration of DNA encoding human papillomavirus (HPV) E6 or E7 antigen with DNA encoding Ii-PADRE led to significantly stronger E6- or E7-specific $\mathrm{CD}^{+} \mathrm{T}$ cell immune responses and more potent protective and therapeutic antitumor effects against an E6/E7-expressing tumor model in mice than did administration of E6 or E7 DNA with Ii DNA (Hung et al., 2007). 
In the current study, we hypothesized that the potency of E7 DNA vaccines employing intracellular targeting strategies (Sig/E7/LAMP-1 DNA or CRT/E7 DNA) with a strategy to prolong the life of antigen-presenting DCs $\left(\mathrm{Bcl}-\mathrm{x}_{\mathrm{L}} \mathrm{DNA}\right)$ can be further enhanced by coadministration of the DNA vaccines with DNA encoding Ii-PADRE. We observed that the addition of DNA encoding Ii-PADRE to the DNA vaccines Sig/E7/LAMP-1 DNA and Bcl$\mathrm{x}_{\mathrm{L}}$ DNA led to significant enhancement of E7-specific $\mathrm{CD} 8^{+}$effector $\mathrm{T}$ cells as well as longterm memory $\mathrm{E} 7$-specific $\mathrm{CD} 8^{+} \mathrm{T}$ cells in vaccinated mice compared with vaccination without Ii-PADRE DNA. We also found that the addition of DNA encoding Ii-PADRE to the DNA vaccines Sig/E7/LAMP-1 DNA and Bcl- $\mathrm{x}_{\mathrm{L}}$ DNA resulted in significantly improved therapeutic effects against established E7-expressing tumors in tumor-challenged mice. The clinical implications of the current study are discussed.

\section{MATERIALS AND METHODS}

Mice

Six- to 8-week-old female C57BL/6 mice were purchased from the National Cancer Institute (Frederick, MD) and housed in the oncology animal facility of Johns Hopkins Hospital (Baltimore, MD). All animal procedures were performed according to approved protocols and in accordance with recommendations for the proper use and care of laboratory animals.

\section{Plasmid DNA constructs and DNA preparation}

The generation of pcDNA-Ii and pcDNA-Ii-PADRE has been described previously (Hung et al., 2007). pcDNA3 plasmids encoding Sig/E7/LAMP-1 (Ji et al., 1999) and CRT/E7 (Cheng et al., 2001a) and pSG5 plasmids encoding Bcl- $\mathrm{x}_{\mathrm{L}}$ (Kim et al., 2003b) were generated as described previously. The DNAs were amplified and purified as described previously (Chen et al., 2000).

\section{DNA vaccination with a gene gun}

DNA-coated gold particles were prepared according to a previously described protocol (Chen et al., 2000). DNA-coated gold particles were delivered to the shaved abdominal region of mice, using a helium-driven gene gun (Bio-Rad, Hercules, CA) with a discharge pressure of $400 \mathrm{lb} / \mathrm{in}^{2}$. C57BL/6 mice were immunized with various combinations of the DNA constructs. The combinations of DNA constructs are illustrated in Tables 1 and 2. Each cartridge contained $0.99 \mu \mathrm{g}$ of plasmid DNA mixture $(0.99 \mu \mathrm{g} / \mathrm{bullet})$ and mice received two shots per mouse of the DNA mixtures by gene gun bombardment for a total of $1.98 \mu \mathrm{g} /$ mouse. Each mouse received a booster of the same dose and regimen 1 week later.

\section{Intracellular cytokine staining and flow cytometric analysis}

Splenocytes were harvested from mice (five per group) 1 week or 60 days after the last vaccination. Before intracellular cytokine staining, pooled splenocytes $\left(5 \times 10^{6} / \mathrm{mouse}\right)$ from each vaccination group were incubated for $16 \mathrm{hr}$ with E7 peptide (RAHYNIVTF, $1 \mu \mathrm{g} / \mathrm{ml}$ ) containing an MHC class I epitope (amino acids 49-57) for detecting antigen-specific CD8 ${ }^{+}$ $\mathrm{T}$ cell precursors. Intracellular interferon (IFN)- $\gamma$ staining and flow cytometric analysis were performed as described previously (Chen et al., 2000). Analysis was performed on a BD FACScan with CellQuest software (BD Biosciences Immunocytometry Systems, Mountain View, CA).

\section{In vivo tumor treatment experiment}

For the tumor treatment experiment, C57BL/6 mice (five per group) were challenged with TC-1 tumor cells $\left(5 \times 10^{4} /\right.$ mouse) by subcutaneous injection into the right leg. Three days after challenge with TC-1 tumor cells, mice were administered the designated plasmid DNA 
mixture (1.98 $\mu \mathrm{g} / \mathrm{mouse})$, via gene gun three times at 4-day intervals. Tumor growth was monitored by visual inspection and palpation twice weekly as described previously (Lin $e t$ al., 1996).

\section{Long-term in vivo tumor protection experiment}

For the long-term tumor protection experiment, mice (five per group) were vaccinated with the designated plasmid DNA mixture (1.98 $\mu \mathrm{g} /$ mouse), using the gene gun. After 1 week, mice were boosted with the same regimen as the first vaccination. On day 60 after the last vaccination, mice were subcutaneously challenged in the right leg with TC-1 tumor cells (3 $\times 10^{5} /$ mouse). Tumor growth was monitored by visual inspection and palpation twice weekly as described previously (Lin et al., 1996).

\section{Tumor measurement and conditional survival}

Three-dimensional tumor sizes were measured two or three times per week with Vernier calipers. Tumor sizes were approximated by multiplying the measured lengths. From day 30 after challenge with tumor cells, tumors were measured every other day, and mice with tumor sizes $>19 \mathrm{~mm}$ in diameter or projected tumor volumes $>10 \%$ body weight or $>2700$ $\mathrm{mm}^{3}$ were considered moribund and killed. Tumor volume was calculated according to the following formula: $V=(L \times W \times D)$, where $V$ is tumor volume, $L$ is length, $W$ is width, and $D$ is depth. The Institutional Animal Care and Use Committee at Johns Hopkins Hospital approved all of the animal studies.

\section{Statistical analysis}

All data expressed as means \pm SD or as means \pm SE are representative of at least two independent experiments. Comparisons between individual data points were made by Student $t$ test. Kaplan-Meier survival curves for tumor treatment and protection experiments were applied; to determine the significance of differences between curves, $p$ values were calculated by log-rank test. $p<0.05$ was considered significant.

\section{RESULTS}

Potency of pcDNA3-Sig/E7/LAMP-1 and $p S G 5-B c l-x_{L}$ DNA vaccines can be further enhanced by pcDNA3-li-PADRE DNA to generate stronger E7-specific CD8+ $T$ cell responses in vaccinated mice

We have previously shown that the potency of E7 DNA vaccines employing intracellular targeting strategies (Sig/E7/LAMP-1 DNA) can be significantly improved with a strategy to prolong the life of antigen-presenting DCs (Bcl- $\mathrm{x}_{\mathrm{L}} \mathrm{DNA}$ ) (Kim et al., 2003a). To explore whether DNA encoding Ii-PADRE (Hung et al., 2007) is capable of further enhancing vaccination with Sig/E7/LAMP-1 and Bcl- $\mathrm{x}_{\mathrm{L}}$ DNA, we immunized mice with all three DNA constructs intradermally, using a gene gun. Additional groups of C57BL/6 mice were immunized with the control DNA vaccine mixtures outlined in Table 1 for comparison. One week after the last vaccination, splenocytes were harvested and characterized for the presence of E7-specific $\mathrm{CD}^{+} \mathrm{T}$ cells, using intracellular cytokine staining for IFN- $\gamma$ followed by flow cytometric analysis. As shown in Fig. 1, mice vaccinated with the Sig/E7/ LAMP-1+Bcl- $\mathrm{x}_{\mathrm{L}}+\mathrm{Ii}-\mathrm{PADRE}$ DNA combination vaccine generated the highest number of E7-specific $\mathrm{CD} 8^{+} \mathrm{T}$ cells of all the DNA-vaccinated mice groups. Mice vaccinated with this combination of DNA generated close to nine times the number of E7-specific $\mathrm{CD} 8^{+} \mathrm{T}$ cells generated in mice vaccinated with the Sig/E7/LAMP-1+pSG5+Ii DNA combination. Mice vaccinated with Sig/E7/LAMP-1+Bcl- $\mathrm{L}_{\mathrm{L}}+\mathrm{Ii}$ DNA or Sig/E7/LAMP-1+pSG5+Ii-PADRE DNA generated approximately two times as many E7-specific CD8 ${ }^{+} \mathrm{T}$ cells as were generated by mice vaccinated with Sig/E7/LAMP-1+pSG5+Ii DNA. Thus, our data suggest 
that DNA encoding Ii-PADRE can be used to further enhance the potency of Sig/E7/ LAMP-1 DNA with Bcl- $\mathrm{x}_{\mathrm{L}}$ DNA vaccines and its addition generates stronger E7-specific $\mathrm{CD}^{+} \mathrm{T}$ cell responses in vaccinated mice. In general, we have found that the ability of $\mathrm{T}$ cells to produce IFN- $\gamma$ correlates with cytotoxicity (Ji et al., 1999; Cheng et al., 2001b; Hung et al., 2001).

We also checked PADRE-specific CD $4^{+} \mathrm{T}$ cell responses in vaccinated mice. It is now known that $\mathrm{CD}^{+} \mathrm{T}$ cell help is required for $\mathrm{CD} 8^{+} \mathrm{T}$ cell activation, although the mechanism is not fully understood. We found that vaccination of mice with DNA combinations containing Ii-PADRE were capable of generating PADRE-specific IFN- $\gamma$-secreting $\mathrm{CD}^{+} \mathrm{T}$ cells. The Sig/E7/LAMP-1+Bcl- $\mathrm{x}_{\mathrm{L}}+\mathrm{Ii}-\mathrm{PADRE}$ combination DNA vaccine generated close to twice as many PADRE-specific $\mathrm{CD} 4^{+} \mathrm{T}$ cells as were generated by mice vaccinated with Sig/E7/LAMP-1+pSG5+Ii-PADRE DNA (see Supplementary Fig. 1). We also characterized other cytokines secreted by PADRE-specific $\mathrm{CD} 4^{+} \mathrm{T}$ cells. We found that PADRE-specific $\mathrm{CD}^{+} \mathrm{T}$ cells secreted high levels of interleukin (IL)-2 and IFN- $\gamma$, but not IL-4 and IL-10, thus suggesting a T helper cell type 1 (Th1) cytokine profile (D.J. Kim, personal communication). Taken together, our data suggest that the PADRE-specific CD4 ${ }^{+} \mathrm{T}$ cells generated with Ii-PADRE DNA can be further improved with DNA employing an antiapoptotic strategy, such as Bcl- $\mathrm{x}_{\mathrm{L}}$ DNA.

\section{Therapeutic antitumor effects of pcDNA3-Sig/E7/LAMP-1 and pSG5-Bcl- $x_{L}$ DNA vaccines can be further improved by coadministration with pcDNA3-li-PADRE}

To determine whether the observed increase in E7-specific $\mathrm{CD} 8^{+} \mathrm{T}$ cells generated by combining Ii-PADRE DNA with Sig/E7/LAMP-1 DNA and Bcl- $x_{L}$ DNA can be translated into improved antitumor effects, we performed in vivo tumor treatment experiments using the previously characterized E7-expressing tumor model, TC-1 (Lin et al., 1996). C57BL/6 mice were first challenged with TC-1 cells subcutaneously. Three days after tumor challenge, the mice were treated intradermally three times at 4-day intervals with various DNA mixtures (see Table 1). As shown in Fig. 2A, we observed that the Sig/E7/ LAMP-1+Bcl- $\mathrm{x}_{\mathrm{L}}+\mathrm{Ii}-\mathrm{PADRE}$ combination DNA vaccine generated the best therapeutic antitumor effects among all the DNA combinations tested. The Sig/E7/LAMP-1+Bcl- $\mathrm{x}_{\mathrm{L}}+\mathrm{Ii}-$ PADRE combination DNA vaccine also led to prolonged survival of vaccinated mice (Fig. 2B). These data suggest that the therapeutic antitumor effects of the DNA vaccines in challenged mice generated with Sig/E7/LAMP-1 DNA and Bcl- $\mathrm{x}_{\mathrm{L}}$ DNA can be significantly improved by the addition of Ii-PADRE DNA.

\section{Addition of pcDNA3-li-PADRE to pcDNA3-Sig/E7/LAMP-1 and/or pSG5-Bcl-x $\mathrm{L}_{\mathrm{L}}$ DNA vaccines leads to increased $\mathrm{E} 7-$-specific $\mathrm{CD} 8^{+}$memory $\mathrm{T}$ cell response in vaccinated mice}

One important feature of an effective vaccine is the ability to generate long-term memory immune responses. To examine the effects of the addition of Ii-PADRE DNA to Sig/E7/ LAMP-1 DNA and/or Bcl- $x_{L}$ DNA vaccines on the generation of long-term E7-specific memory T cells, we immunized C57BL/6 mice with Sig/E7/LAMP-1+Bcl- $x_{L}+\mathrm{Ii}-\mathrm{PADRE}$ DNA intradermally via gene gun. Additional groups of mice were immunized with the control DNA vaccine mixtures outlined in Table 1 for comparison. Two months after the last vaccination, splenocytes were harvested and characterized for the presence of E7-specific $\mathrm{CD} 8^{+} \mathrm{T}$ cells by intracellular cytokine staining for IFN- $\gamma$ followed by flow cytometric analysis. As shown in Fig. 3, mice vaccinated with the combination of DNA vaccination strategies including Sig/E7/LAMP-1+Bcl- $\mathrm{x}_{\mathrm{L}}+\mathrm{Ii}-\mathrm{PADRE}$ DNA generated the highest number of E7-specific CD8 ${ }^{+}$memory T cells. Mice vaccinated with Sig/E7/LAMP-1+pSG5+IiPADRE DNA also generated significant levels of E7-specific $\mathrm{CD}^{+} \mathrm{T}$ memory cells. Thus, our data suggest that addition of DNA encoding Ii-PADRE to Sig/E7/LAMP-1 and/or Bcl- 
$\mathrm{x}_{\mathrm{L}}$ DNA vaccines leads to an increased $\mathrm{E} 7$-specific $\mathrm{CD} 8^{+}$memory $\mathrm{T}$ cell response in vaccinated mice.

\section{Addition of pcDNA3-li-PADRE to pcDNA3-Sig/E7/LAMP-1 and/or pSG5-Bcl- $x_{L}$ DNA vaccines leads to long-term protective antitumor effects in vaccinated mice}

To determine whether the observed increase in E7-specific $\mathrm{CD}^{+}$memory $\mathrm{T}$ cells generated by combining Ii-PADRE DNA with Sig/E7/LAMP-1 DNA and Bcl- $\mathrm{x}_{\mathrm{L}}$ DNA can be translated into long-term protective antitumor effects, we performed in vivo tumor protection experiments over an extended period of time, using E7-expressing TC-1 cells. C57BL/6 mice were first vaccinated intradermally with the various DNA mixtures (see Table 1). Two months after the last vaccination, immunized mice were challenged subcutaneously with TC-1 tumor cells $\left(3 \times 10^{5} /\right.$ mouse $)$ and then monitored for tumor growth. As shown in Fig. $4 \mathrm{~A}$, mice vaccinated with Sig/E7/LAMP-1+Bcl- $\mathrm{x}_{\mathrm{L}}+\mathrm{Ii}-\mathrm{PADRE}$ DNA demonstrated significant inhibition of tumor growth compared with mice vaccinated with the other DNA vaccine combinations. Furthermore, we observed significantly prolonged survival in these mice (Fig. 4B). These data suggest that the addition of Ii-PADRE DNA to Sig/E7/LAMP-1 and $\mathrm{Bcl}-\mathrm{x}_{\mathrm{L}}$ DNA vaccines can lead to strong long-term protective antitumor effects against TC-1 tumors, leading to prolonged survival.

\section{DNA encoding li-PADRE is capable of enhancing antigen-specific CD8+ T cell immune responses generated by DNA vaccines employing other intracellular targeting strategies}

We have previously shown that DNA vaccines encoding HPV-16 E7 linked to calreticulin (CRT) were capable of generating potent $\mathrm{E} 7$-specific $\mathrm{CD} 8^{+} \mathrm{T}$ cells in vaccinated mice (Cheng et al., 2001a). We have also shown that the potency of E7-specific CD8 ${ }^{+} \mathrm{T}$ cell immune responses generated by CRT/E7 DNA can be improved by coadministration with Bcl- $x_{L}$ DNA (Kim et al., 2003a). To explore whether the addition of DNA encoding IiPADRE is capable of further enhancing the immune response generated by vaccination with CRT/E7 DNA and Bcl- $x_{L}$ DNA, we immunized mice with CRT/E7+Bcl- $x_{L}+$ Ii-PADRE DNA intradermally, using a gene gun. Additional groups of mice were immunized with the control DNA vaccine mixtures outlined in Table 2 for comparison. One week after the last vaccination, splenocytes were harvested and characterized for the presence of E7-specific $\mathrm{CD} 8^{+} \mathrm{T}$ cells by intracellular cytokine staining for IFN $\gamma$ followed by flow cytometric analysis. As shown in Fig. 5, mice vaccinated with CRT/E7+Bcl- $x_{L}+$ Ii-PADRE DNA generated the highest number of $\mathrm{E} 7$-specific $\mathrm{CD} 8^{+} \mathrm{T}$ cells among all the DNA vaccines tested. Mice vaccinated with CRT/E7+Bcl- $\mathrm{x}_{\mathrm{L}}+\mathrm{Ii}-\mathrm{PADRE}$ DNA generated nearly eight times as many E7-specific $\mathrm{CD}^{+} \mathrm{T}$ cells compared with mice vaccinated with $\mathrm{CRT} / \mathrm{E} 7+\mathrm{pSG} 5+\mathrm{Ii}$ DNA. Mice vaccinated with CRT/E7+Bcl- $\mathrm{x}_{\mathrm{L}}+\mathrm{Ii}$ DNA or CRT/E7+pSG5+Ii-PADRE DNA generated approximately two to three times the number of E7-specific $\mathrm{CD} 8^{+} \mathrm{T}$ cells as were generated by mice vaccinated with CRT/E7+pSG5+Ii DNA. Our data suggest that DNA encoding Ii-PADRE can be used to further enhance the potency of DNA vaccines employing other intracellular targeting strategies to generate $\mathrm{E} 7$-specific $\mathrm{CD} 8^{+} \mathrm{T}$ cell responses in vaccinated mice.

\section{DISCUSSION}

Our study demonstrated that E7 DNA vaccines employing intracellular targeting strategies with a strategy to prolong the life of DCs can be further enhanced by the addition of DNA encoding Ii-PADRE. We observed that the addition of Ii-PADRE DNA to Sig/E7/LAMP-1 (or CRT/E7) and/or Bcl- $\mathrm{x}_{\mathrm{L}}$ DNA led to significant enhancement of E7-specific CD8 ${ }^{+}$ effector and memory $\mathrm{T}$ cells as well as potent antitumor effects against E7-expressing tumors in vaccinated mice compared with the other combinations of DNA vaccines listed in Tables 1 and 2. Our observations serve as a foundation for future clinical translation. 
The observed enhancement of DNA vaccine potency employing these strategies requires a system that directly delivers DNA vaccines into professional antigen-presenting cells (APCs). We used intradermal immunization via gene gun to vaccinate mice with the DNA vaccines. It has been shown that intradermal immunization can target DNA directly to Langerhans cells and facilitate direct presentation of the antigen to T cells by DNAtransfected DCs (Condon et al., 1996; Porgador et al., 1998). Because these three strategies represent an opportunity to modify the properties of DCs to enhance T cell activation through different mechanisms, they are not mutually exclusive. As a result, we observed enhancement of the levels of antigen-specific $\mathrm{CD} 8^{+} \mathrm{T}$ cells in vaccinated mice.

In our study, we showed that the addition of DNA encoding Ii-PADRE to the DNA vaccines Sig/E7/LAMP-1 DNA (or CRT/E7) and Bcl- $\mathrm{x}_{\mathrm{L}}$ DNA led to significant levels of E7-specific $\mathrm{CD} 8^{+}$effector and memory $\mathrm{T}$ cells in vaccinated mice. Several models have been proposed to demonstrate the roles of $\mathrm{CD}^{+} \mathrm{T}$ cells in facilitating the generation of antigen-specific $\mathrm{CD}^{+} \mathrm{T}$ cell immune responses. In one model, APCs deliver costimulatory signals to the $\mathrm{CD}^{+}$helper $\mathrm{T}$ cells, which in turn generate interleukin-2. This interleukin-2 production is important for the activation of antigen-specific $\mathrm{CD}^{+} \mathrm{T}$ cells (Mitchison and O'Malley, 1987; Bennett et al., 1997; Xiang et al., 2005). Another model proposes that the contact of $\mathrm{CD}^{+} \mathrm{T}$ cells with APCs leads to the maturation of APCs, which subsequently leads to activation of CD8 ${ }^{+} \mathrm{T}$ cells (Bousso and Robey, 2003; Bevan, 2004; Xiang et al., 2005). A more recently proposed model suggests that APCs can directly transfer costimulatory molecules as well as MHC class I antigen complexes to expanding populations of IL-2secreting helper T cells, which then function as APCs to stimulate cytotoxic T lymphocyte (CTL) activation directly (Xiang et al., 2005). Dendritic cells and CD4 ${ }^{+} \mathrm{T}$ cell interactions have also been shown to lead to the production of CCL3 and CCL4 chemokines (also known as macrophage inflammatory protein MIP- $1 \alpha$ and MIP- $1 \beta$ ). These chemokines may be important for bringing in antigen-specific $\mathrm{CD} 8^{+} \mathrm{T}$ cells to the antigen-expressing dendritic cells (Castellino et al., 2006). Thus, $\mathrm{CD} 4^{+}$helper T cells are important for the generation of antigen-specific effector and memory $\mathrm{CD} 8^{+} \mathrm{T}$ cells.

In summary, we observed that the potency of E7 DNA vaccines employing intracellular targeting strategies (Sig/E7/LAMP-1 DNA or CRT/E7 DNA) with a strategy to prolong the life of DCs (Bcl- $x_{L}$ DNA) can be further enhanced by coadministration of DNA vaccines with DNA encoding Ii-PADRE. It is conceivable that the future of DNA vaccine development will require the combination of various strategies that are capable of enhancing DNA vaccines through different mechanisms in order to generate the most potent effects. Thus, our current study serves as an important foundation for future clinical translation.

\section{Supplementary Material}

Refer to Web version on PubMed Central for supplementary material.

\section{Acknowledgments}

The authors thank Ms. Archana Monie for help with preparation of the manuscript. This work was supported by 1RO1-CA114425-01 and P50-CA098252 (Cervical Cancer SPORE Program) of the National Cancer Institute.

\section{References}

BENNETT SR, CARBONE FR, KARAMALIS F, MILLER JF, HEATH WR. Induction of a CD8 ${ }^{+}$ cytotoxic $\mathrm{T}$ lymphocyte response by cross-priming requires cognate $\mathrm{CD} 4^{+} \mathrm{T}$ cell help. J Exp Med. 1997; 186:65-70. [PubMed: 9206998]

BEVAN MJ. Helping the CD8 ${ }^{+}$T-cell response. Nat Rev Immunol. 2004; 4:595-602. [PubMed: 15286726] 
BOUSSO P, ROBEY E. Dynamics of CD8 ${ }^{+} \mathrm{T}$ cell priming by dendritic cells in intact lymph nodes. Nat Immunol. 2003; 4:579-585. [PubMed: 12730692]

CASTELLINO F, GERMAIN RN. Cooperation between $\mathrm{CD}^{+}{ }^{+}$and $\mathrm{CD} 8^{+} \mathrm{T}$ cells: When, where, and how. Annu Rev Immunol. 2006; 24:519-540. [PubMed: 16551258]

CASTELLINO F, HUANG AY, ALTAN-BONNET G, STOLL S, SCHEINECKER C, GERMAIN RN. Chemokines enhance immunity by guiding naive $\mathrm{CD}^{+} \mathrm{T}$ cells to sites of $\mathrm{CD} 4^{+} \mathrm{T}$ celldendritic cell interaction. Nature. 2006; 440:890-895. [PubMed: 16612374]

CHEN CH, WANG TL, HUNG CF, YANG Y, YOUNG RA, PARDOLL DM, WU TC. Enhancement of DNA vaccine potency by linkage of antigen gene to an HSP70 gene. Cancer Res. 2000; 60:10351042. [PubMed: 10706121]

CHENG WF, HUNG CF, CHAI CY, HSU KF, HE L, LING M, WU TC. Tumor-specific immunity and antiangiogenesis generated by a DNA vaccine encoding calreticulin linked to a tumor antigen. $\mathrm{J}$ Clin Invest. 2001a; 108:669-678. [PubMed: 11544272]

CHENG WF, HUNG CF, CHAI CY, HSU KF, HE L, RICE CM, LING M, WU TC. Enhancement of Sindbis virus self-replicating RNA vaccine potency by linkage of Mycobacterium tuberculosis heat shock protein 70 gene to an antigen gene. J Immunol. 2001b; 166:6218-6226. [PubMed: 11342644]

CONDON C, WATKINS SC, CELLUZZI CM, THOMPSON K, FALO LD JR. DNA-based immunization by in vivo transfection of dendritic cells. Nat Med. 1996; 2:1122-1128. [PubMed: 8837611]

HUNG CF, CHENG WF, HSU KF, CHAI CY, HE L, LING M, WU TC. Cancer immunotherapy using a DNA vaccine encoding the translocation domain of a bacterial toxin linked to a tumor antigen. Cancer Res. 2001; 61:3698-3703. [PubMed: 11325841]

HUNG CF, YANG M, WU TC. Modifying professional antigen-presenting cells to enhance DNA vaccine potency. Methods Mol Med. 2006; 127:199-220. [PubMed: 16988456]

HUNG CF, TSAI YC, HE L, WU TC. DNA vaccines encoding Ii-PADRE generate potent PADREspecific $\mathrm{CD}^{+}{ }^{+}$T-cell immune responses and enhances vaccine potency. Mol Ther. 2007; 15:12111219. [PubMed: 17356542]

JI H, WANG TL, CHEN CH, PAI SI, HUNG CF, LIN KY, KURMAN RJ, PARDOLL DM, WU TC. Targeting human papillomavirus type $16 \mathrm{E} 7$ to the endosomal/lysosomal compartment enhances the antitumor immunity of DNA vaccines against murine human papillomavirus type 16 E7expressing tumors. Hum Gene Ther. 1999; 10:2727-2740. [PubMed: 10584920]

KIM TW, HUNG CF, BOYD D, JUANG J, HE L, KIM JW, HARDWICK JM, WU TC. Enhancing DNA vaccine potency by combining a strategy to prolong dendritic cell life with intracellular targeting strategies. J Immunol. 2003a; 171:2970-2976. [PubMed: 12960321]

KIM TW, HUNG CF, LING M, JUANG J, HE L, HARDWICK JM, KUMAR S, WU TC. Enhancing DNA vaccine potency by coadministration of DNA encoding antiapoptotic proteins. J Clin Invest. 2003b; 112:109-117. [PubMed: 12840065]

LIN KY, GUARNIERI FG, STAVELEY-O'CARROLL KF, LEVITSKY HI, AUGUST JT, PARDOLL DM, WU TC. Treatment of established tumors with a novel vaccine that enhances major histocompatibility class II presentation of tumor antigen. Cancer Res. 1996; 56:21-26. [PubMed: 8548765]

MITCHISON NA, O'MALLEY C. Three-cell-type clusters of T cells with antigen-presenting cells best explain the epitope linkage and noncognate requirements of the in vivo cytolytic response. Eur J Immunol. 1987; 17:1579-1583. [PubMed: 2445585]

MONIZ M, LING M, HUNG CF, WU TC. HPV DNA vaccines. Front Biosci. 2003; 8:d55-d68. [PubMed: 12456324]

PORGADOR A, IRVINE KR, IWASAKI A, BARBER BH, RESTIFO NP, GERMAIN RN. Predominant role for directly transfected dendritic cells in antigen presentation to $\mathrm{CD}^{+} \mathrm{T}$ cells after gene gun immunization. J Exp Med. 1998; 188:1075-1082. [PubMed: 9743526]

TSEN SW, PAIK AM, HUNG CF, WU TC. Enhancing DNA vaccine potency by modifying the properties of antigen-presenting cells. Expert Rev Vaccines. 2007; 6:227-239. [PubMed: 17408372]

XIANG J, HUANG H, LIU Y. A new dynamic model of $\mathrm{CD}^{+} \mathrm{T}$ effector cell responses via CD4 ${ }^{+} \mathrm{T}$ helper-antigen-presenting cells. J Immunol. 2005; 174:7497-7505. [PubMed: 15944248] 
(A)

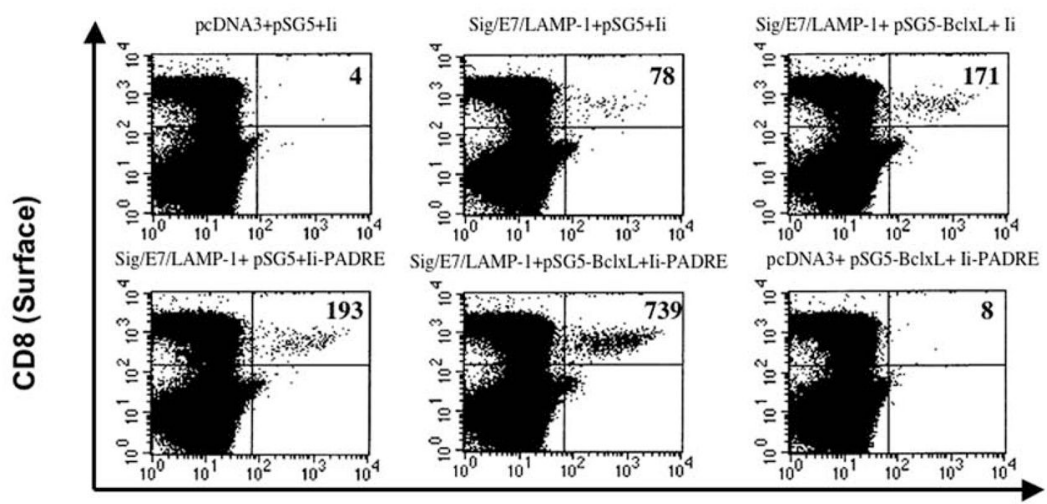

IFN- $\gamma$ (intracellular)

(B)

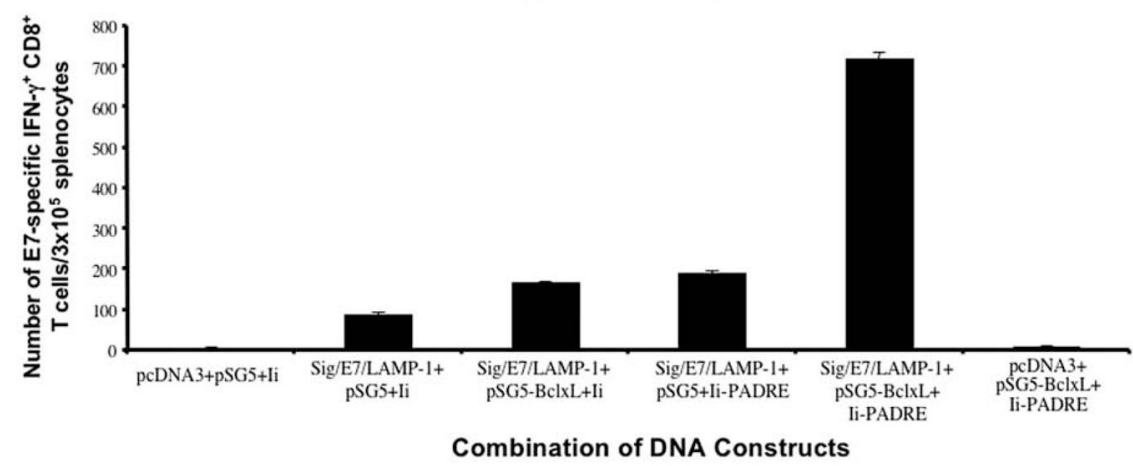

FIG. 1.

Flow cytometric analysis of E7-specific $\mathrm{CD}^{+} \mathrm{T}$ cells in mice vaccinated with various DNA vaccines. C57BL/6 mice (five per group) were immunized, at $1.98 \mu \mathrm{g}$ of DNA per mouse, with various DNA vaccine mixtures (listed in Table 1) twice with a 1-week interval. Splenocytes from vaccinated mice were harvested 1 week after the last vaccination and characterized for E7-specific $\mathrm{CD} 8^{+} \mathrm{T}$ cells, using intracellular IFN- $\gamma$ staining followed by flow cytometric analysis. (A) Representative flow cytometric data. Numbers in the upper right-hand corners represent the number of E7-specific IFN- $\gamma$-secreting CD8 ${ }^{+} \mathrm{T}$ cells per $5 \times$ $10^{6}$ pooled splenocytes. (B) Bar graph depicting numbers of E7-specific IFN- $\gamma$-secreting $\mathrm{CD}^{+} \mathrm{T}$ cells per $3 \times 10^{5}$ pooled splenocytes (means $+\mathrm{SD}$ ). Data are from one representative experiment of two performed. 
(A)

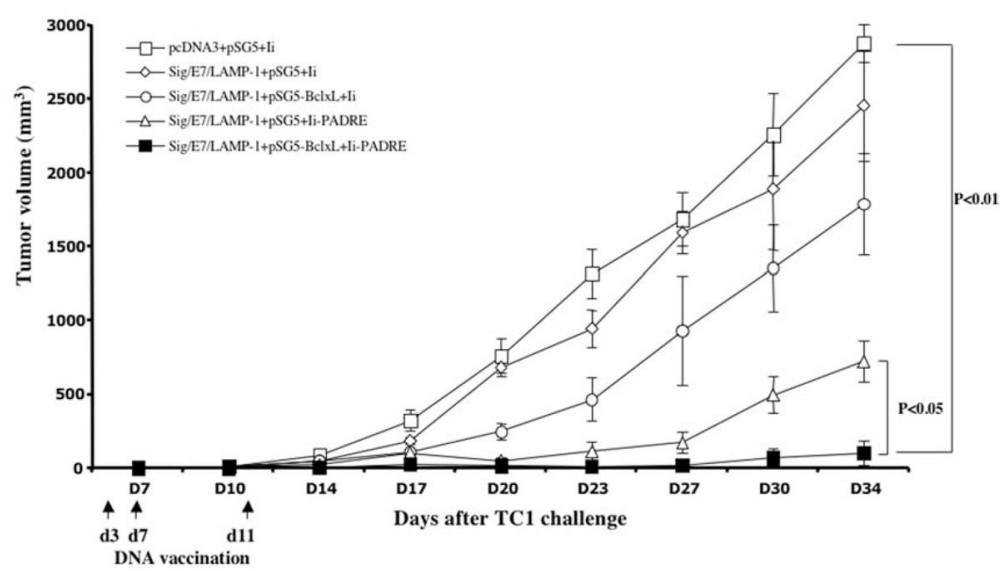

(B)

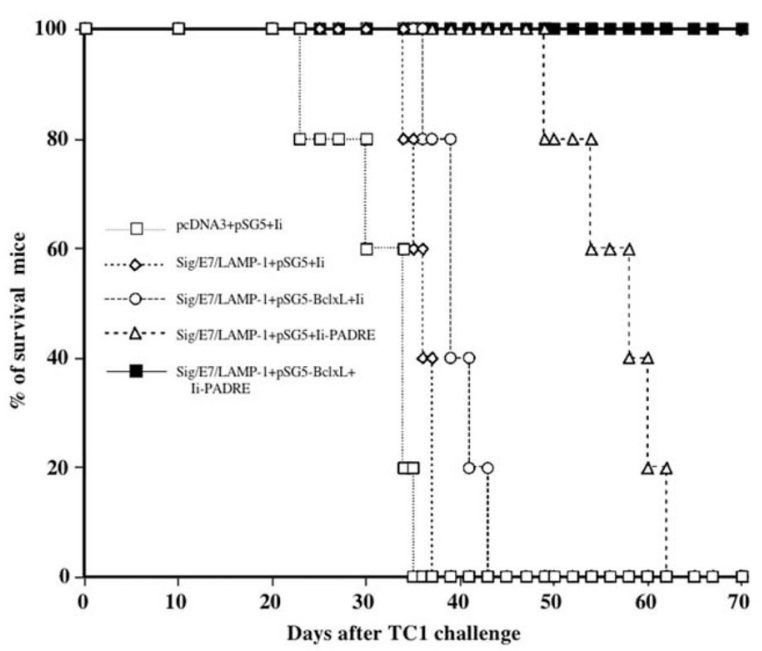

FIG. 2.

In vivo treatment experiments. C57BL/6 mice (five per group) were first challenged by subcutaneous injection with TC1 tumor cells $\left(5 \times 10^{4} /\right.$ mouse). Three days after tumor challenge, the mice were administered, at $1.98 \mu \mathrm{g}$ of DNA per mouse, various DNA vaccine mixtures (listed in Table 1) three times with 4-day intervals. The mice were monitored for evidence of tumor growth by inspection and palpitation twice per week. Tumor volume was measured starting from day 7 after tumor challenge. (A) Line graph depicting tumor volume in mice in the tumor treatment experiments (means \pm SE). (B) Kaplan-Meier survival analysis of mice in the tumor treatment experiments. Data shown are from one representative experiment of two performed. 
(A)

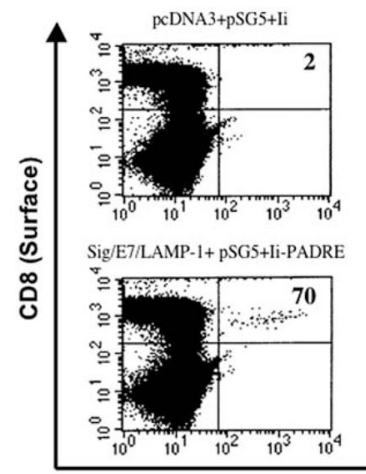

(B)

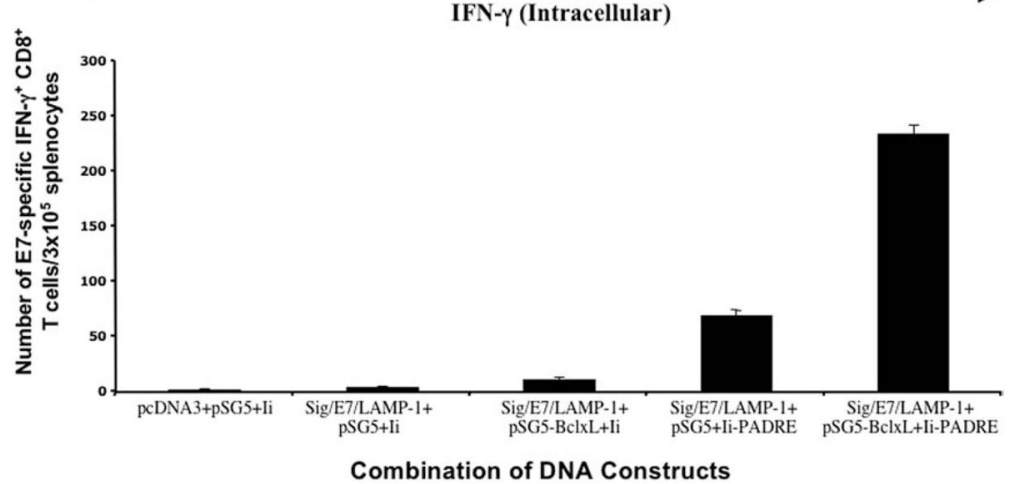

$\mathrm{Sig} / \mathrm{E} 7 \mathrm{LAMP}-1+$ pSG5+li

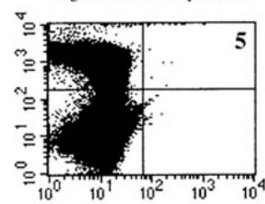

Sig/E7/LAMP-1+ pSG5-BclxL+li

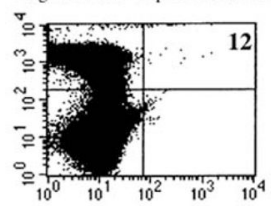

Sig/E7/LAMP-1+pSG5-BelxL+li-PADRE

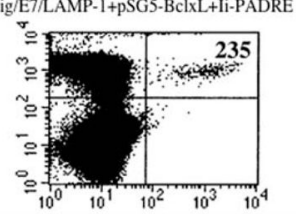

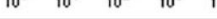

IFN- $\gamma$ (Intracellular)
Combination of DNA Constructs

FIG. 3.

Flow cytometric analysis of $\mathrm{E} 7$-specific $\mathrm{CD} 8^{+} \mathrm{T}$ cells in mice vaccinated with various DNA vaccine combinations 2 months after vaccination. C57BL/6 mice (five per group) were immunized, at $1.98 \mu \mathrm{g}$ of DNA per mouse, with various DNA vaccine mixtures (listed in Table 1) twice with a 1-week interval. Splenocytes from vaccinated mice were harvested 2 months after the last vaccination and characterized for E7-specific $\mathrm{CD} 8^{+} \mathrm{T}$ cells, using intracellular IFN- $\gamma$ staining followed by flow cytometric analysis. (A) Representative flow cytometric data. Numbers in the upper right-hand corner represent the number of E7-specific IFN- $\gamma$-secreting $\mathrm{CD} 8^{+} \mathrm{T}$ cells per $5 \times 10^{6}$ pooled splenocytes 2 months after the last vaccination. (B) Bar graph depicting the numbers of E7-specific IFN- $\gamma$-secreting CD8 ${ }^{+} \mathrm{T}$ cells per $3 \times 10^{5}$ pooled splenocytes 2 months after the last vaccination (means $+\mathrm{SD}$ ). Data are from one representative experiment of two performed. 
(A)

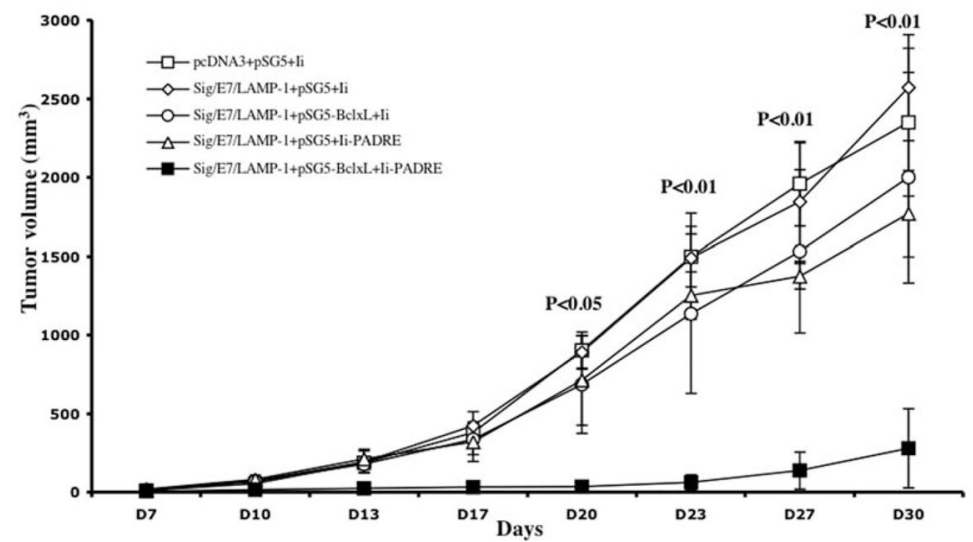

(B)

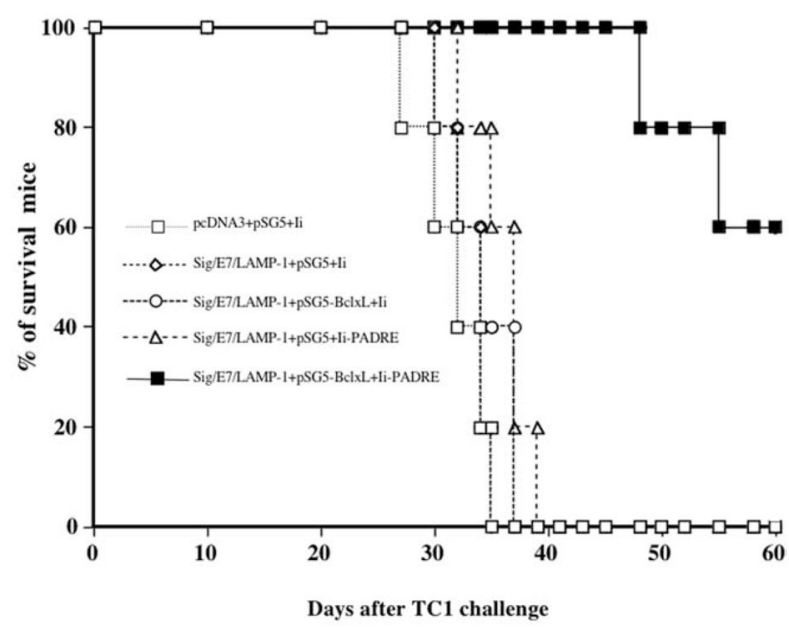

FIG. 4.

Long-term in vivo tumor protection experiments. C57BL/6 mice (five per group) were immunized, at $1.98 \mu \mathrm{g}$ of DNA per mouse, with various DNA vaccine mixtures (listed in Table 1) twice with a 1-week interval. Two months after the last vaccination, the mice were challenged by subcutaneous injection of TC- 1 cells $\left(3 \times 10^{5} / \mathrm{mouse}\right)$. The mice were monitored for evidence of tumor growth by inspection and palpitation twice per week. Tumor volume was measured starting from day 7 after tumor challenge. (A) Line graph depicting tumor volume in mice challenged with TC-1 cells (means \pm SE). (B) KaplanMeier survival analysis of mice challenged with TC-1 cells. Data are from one representative experiment of two performed. 
(A)

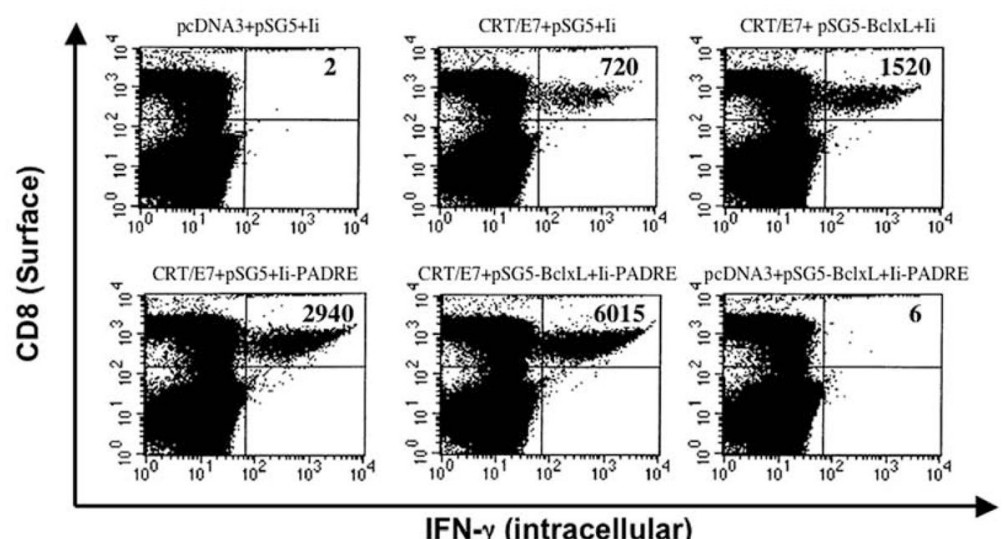

(B)

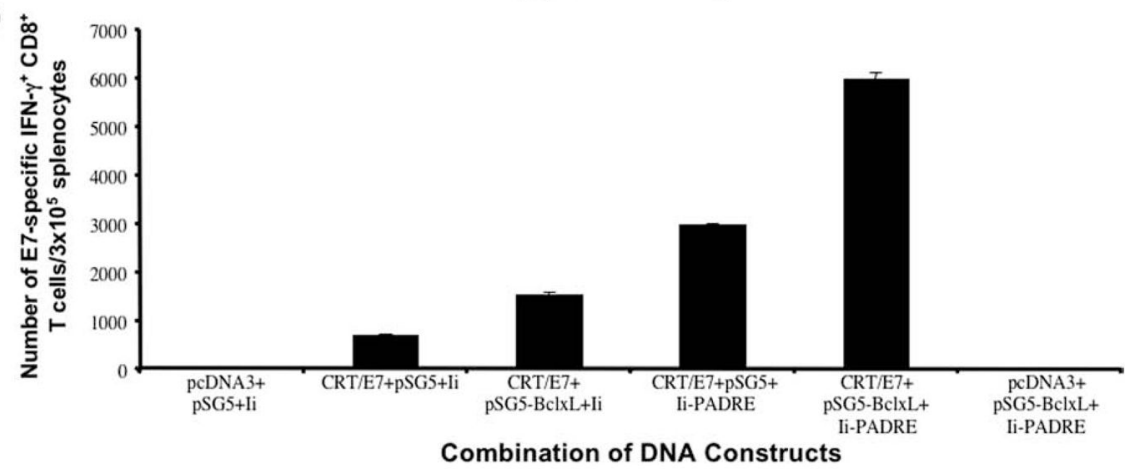

FIG. 5.

Flow cytometric analysis of E7-specific $\mathrm{CD} 8^{+} \mathrm{T}$ cells in DNA-vaccinated mice. C57BL/6 mice (five per group) were immunized, at $1.98 \mu \mathrm{g}$ of DNA per mouse, with various DNA vaccine mixtures (listed in Table 2) twice with a 1-week interval. Splenocytes from vaccinated mice were harvested 1 week after the last vaccination and characterized for E7specific $\mathrm{CD} 8^{+} \mathrm{T}$ cells, using intracellular IFN- $\gamma$ staining followed by flow cytometric analysis. (A) Representative flow cytometric data. Numbers in the upper right-hand corners represent the number of E7-specific IFN- $\gamma$-secreting $\mathrm{CD} 8^{+} \mathrm{T}$ cells per $5 \times 10^{6}$ pooled splenocytes. (B) Bar graph depicting the numbers of E7-specific IFN- $\gamma$-secreting CD $8^{+} \mathrm{T}$ cells per $3 \times 10^{5}$ pooled splenocytes (means $+\mathrm{SD}$ ). Data are from one representative experiment of two performed. 
Table 1

Vaccination of Mice with Various DNA Combinations with Sig/E7/LAMP-1 DNA

\begin{tabular}{|c|c|c|c|c|}
\hline \multirow[b]{2}{*}{ Mouse group \# } & \multicolumn{3}{|c|}{ DNA construct used in mixture } & \multirow[b]{2}{*}{ Notes } \\
\hline & Component 1 & Component 2 & Component 3 & \\
\hline 1 & pcDNA3 & pSG5 & pcDNA3-Ii & \\
\hline 2 & pcDNA3-Sig/E7/LAMP-1 & pSG5 & pcDNA3-Ii & \\
\hline 3 & pcDNA3-Sig/E7/LAMP-1 & pSG5-Bcl- $\mathrm{x}_{\mathrm{L}}$ & pcDNA3-Ii & \\
\hline 4 & pcDNA3-Sig/E7/LAMP-1 & pSG5 & pcDNA3-Ii-PADRE & \\
\hline 5 & pcDNA3-Sig/E7/LAMP-1 & pSG5-Bcl- $\mathrm{x}_{\mathrm{L}}$ & pcDNA3-Ii-PADRE & \\
\hline 6 & pcDNA3 & pSG5-Bcl- $x_{L}$ & pcDNA3-Ii PADRE & \\
\hline 7 & pcDNA3 & pSG5-Bcl- $x_{L}$ & pcDNA3-Ii & Not done \\
\hline 8 & pcDNA3 & pSG5 & pcDNA3-Ii-PADRE & Not done \\
\hline Amount of DNA in one bullet & $0.33 \mu \mathrm{g}$ & $0.33 \mu \mathrm{g}$ & $0.33 \mu \mathrm{g}$ & Total DNA $=0.99 \mu \mathrm{g} / \mathrm{bullet}$ \\
\hline
\end{tabular}

Abbreviations: pcDNA3 and pSG5, vector backbones; Sig, endosomal/lysosomal signal; E7, human papillomavirus type 16 E7 protein; LAMP-1, lysosomal-associated membrane protein-1; Bcl-xL, B cell lymphoma/leukemia isoform extra long; Ii, invariant chain; PADRE, pan-HLA-DRbinding epitope. 
Table 2

Vaccination of Mice with Various DNA Combinations with CRT-E7 DNA

\begin{tabular}{|c|c|c|c|c|}
\hline \multirow[b]{2}{*}{ Mouse group } & \multicolumn{3}{|c|}{ DNA construct used in mixture } & \multirow[b]{2}{*}{ Notes } \\
\hline & Component 1 & Component 2 & Component 3 & \\
\hline 1 & pcDNA3 & pSG5 & pcDNA3-Ii & \\
\hline 2 & pcDNA3-CRT/E7 & pSG5 & pcDNA3-Ii & \\
\hline 3 & pcDNA3-CRT/E7 & pSG5-Bcl- $\mathrm{x}_{\mathrm{L}}$ & pcDNA3-Ii & \\
\hline 4 & pcDNA3-CRT/E7 & pSG5 & pcDNA3-Ii PADRE & \\
\hline 5 & pcDNA3-CRT/E7 & pSG5-Bcl- $\mathrm{x}_{\mathrm{L}}$ & pcDNA3-Ii-PADRE & \\
\hline 6 & pcDNA3 & pSG5-Bcl- $\mathrm{x}_{\mathrm{L}}$ & pcDNA3-Ii-PADRE & \\
\hline 7 & pcDNA3 & pSG5-Bcl- $\mathrm{x}_{\mathrm{L}}$ & pcDNA3-Ii & Not done \\
\hline 8 & pcDNA3 & pSG5 & pcDNA3-Ii-PADRE & Not done \\
\hline Amount of DNA in one bullet & $0.33 \mu \mathrm{g}$ & $0.33 \mu \mathrm{g}$ & $0.33 \mu \mathrm{g}$ & Total DNA $=0.99 \mu \mathrm{g} / \mathrm{bullet}$ \\
\hline
\end{tabular}

Abbreviations: CRT, calreticulin; see also Table 1. 